\title{
KOMPOSISI MUSIK BADONDONG BAIBO DALAM MUSIK INSTRMENTAL
}

\author{
Ferry Herdianto $^{1 *}$, Yusnelli2* ${ }^{*}$ Freddy Antara ${ }^{3^{*}}$ \\ Program Studi Seni Musik Fakultas Seni Pertunjukan \\ Institut Seni Indonesia Padangpanjang \\ Jl. Bahder Johan, Guguak Malintang, Padangpanjang, Kota Padangpanjang, Kode Pos 27126 \\ Sumatera Barat. Indonesia \\ Email: titokferry@gmail.com,yusnelli63@gmail.com,freddyhafanis@gmail.com
}

\begin{abstract}
Abstrak
Rumusan penciptaan komposisi ini diwujudkan dalam sebuah pertunjukan yaitu musik instrumental dan vokal yang mengangkat kesenian badondong baibo menjadi sebuah pertunjukan musik instrumental yang kreatif dan inovatif dalam bentuk komposisi musik dengan format orketra. Dimana rumusan penciptaan menggunakan prinsip-prinsip ilmu musik konvensional. Sedangkan tujuan penciptaan ini adalah 1) untuk menghadirkan kesenian badondong baibo dengan konteks dan fungsi yang berbeda ke dalam komposisi musik modern dan mengembangkannya dengan menggunakan teknik konvensional, 2) untuk merealisasikan ide musikal yang di inspirasi dari kesenian badondong baibo dan menjadikannya sebuah komposisi musik yang baru. Sedangkan metode penciptaan dilakukan dengan tiga tahap yaitu; 1) tahap pengumpulan data, 2) tahap penciptaan dan 3) tahap evaluasi. Secara aris besar kompisisi ini dapat disimpulkan bahwa; a) menggarap sebuah komposisi yang berangkat dari sebuah kesenian bukanlah perkara yang mudah, selain harus memahami, kita juga dituntut untuk mempelajari latar belakang dari kesenian tersebut, b) badondong adalah komposisi musik baru yang bersumber dari melodi vocal badondong baibo yang terdapat didaerah Danto kecamatan Kampar Timur, c) material komposisi ini adalah potongan-potongan melodi "nandung-nandung" yang dikembangkan dengan tidak menghilangkan nuasa melodi pokok "nandung-nandung”, d) vokal dari badondong baibo dibawakan oleh seorang vokalis untuk memperkenalkan tema pokok dalam penggarapan komposisi ini, e) komposisi digarap dengan format orkestra dalam sebuah pertunjukan seni, f) badondong ini adalah sebuah komposisi musik yang dicipatkan dengan menggunakan banyak pengembangan, dimana komposisi musik ini dihadirkan dalam konteks prtunjukan.
\end{abstract}

Kata Kunci: badondong, baibo, komposisi, musik.

\begin{abstract}
The formulation of the creation of this composition is manifested in a performance, namely instrumental and vocal music that elevates the art of Badondong Baibo into a creative and innovative instrumental music performance in the form of musical compositions in the orchestra format. Where the creation formula uses the principles of conventional music science. While the purpose of this creation is 1) to present the art of Badondong Baibo with different contexts and functions into modern musical compositions and to develop it using conventional techniques, 2) to realize musical ideas inspired by the art of Badondong Baibo and make it a new musical composition. . While the method of creation is carried out in three stages, namely; 1) the data collection stage, 2) the creation stage and 3) the evaluation stage. From a large scale of this composition it can be concluded that; a) working on a composition that departs from an art is not an easy matter, apart from having to understand, we are also required to learn the background of the art, b) badondong is a new musical composition that comes from the vocal melody of Badondong Baibo found in the Danto area, Kampar sub-district Timur, c) the material of this composition is pieces of the melody "nandung-nandung" which are developed without eliminating the main melodic tone of "nandung-nandung", d) the vocal from badondong baibo is delivered by a vocalist to introduce the main theme in the work of this composition e) the composition is made in an orchestral format in an art performance, f) This badondong is a musical composition created using a lot of development, where this musical composition is presented in the context of an art show.
\end{abstract}

Keywords: badondong, baibo, composition, music. 


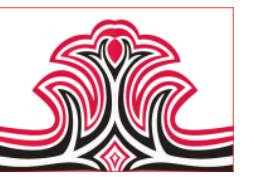

\section{PENDAHULUAN}

Kehidupan masyarakat suatu daerah pada umumnya dipengaruhi oleh kebudayaan sebagai suatu kebiasaan yang selalu diulang-ulang, dilestarikan dan dipertahankan keasliannya, sehingga menjadi identitas suatu daerah, baik dalam bidang kesenian, sosial, ekonomi dan politik. Sebagaiman yang disampaikan oleh Mahdayeni, at al (2019) kebudayaan adalah produk manusia, namun manusia itu sendiri adalah produk kebudayaan. Dengan kata lain, kebudayaan ada karena manusia yang menciptakannya dan manusia dapat hidup ditengah kebudayaan yang diciptakannya. Kebudayaan akan terus hidup manakala ada manusia sebagai pendudukungnya dan kebudayaan mempunyai kegunaan yang sangat besar bagi manusia di dalam kehidupannya. Menurut Maran (2007) Kebudayaan secara jelas menampakkan kesamaan kodrat manusia dari berbagai suku, bangsa, dan ras. Sedangkan menurut Sahar (2015) Setiap kebudayaan pasti memiliki wadah dan masyarakat adalah wadah dari kebudayaan tersebut, sehingga antara kebudayaan dan masyarakat keduanya tidak dapat dipisahkan.

Mengenai pengertian budaya Baran (2012) mengatakan bahwa budaya adalah tradisi dan gaya hidup yang dipelajari dan didapatkan secara sosial oleh anggota dalam suatu masyarakat, termasuk cara berpikir, perasaan, dan tindakan yang terpola dan dilakukan berulang-ulang. Menurut Esten (1990) tradisi adalah kebiasaan turun temuru sekelompok masyarakat berdasarkan nilai budaya masyarakat yang bersangkutan. Tradisi memperlihatkan bagaimana masyarakat bertingkah laku, baik dalam kehidupan yang bersifat duniawi maupun yang bersifat gaib atau keagamaan. Seperti halnya kebiasaan badondong yang dilakukan oleh masyarakat bangkinang. Yohana (2015) menjelaskan tradisi merupakan salah satu bentuk ekspresi kebudayaan daerah dan merupakan bagian kekuatan kultural suatu bangsa. Tradisi merupakan alat komunikasi yang digunakan oleh komunitas untuk menyampaikan maksud sesuai dengan bahasa suatu daerah dan aturan adat yang berlaku. Penuturan dan penyampaian tradisi lisan ini tidak hanya berupa kata, tetapi merupakan gabungan dari kata dan perbuatan yang menyertai kata-kata tersebut.

Sibarani (2015: 72) menyatakan wujud tradisi lisan dapat berupa (1) tradisi berbahasa dan beraksara lokal, (2) tradisi berkesusastraan, (3) tradisi pertunjukan, (4) tradisi upacara adat, (5) tradisi teknologi tradisional, (6) tradisi perlambangan, (7) tradisi seni dan musik rakyat, (8) tradisi pertanian tradisional, (9) tradisi kerajinan tangan, (10) tradisi kuliner, (11) tradisi obat-obatan atau pengobatan tradisional, dan (12) tradisi panorama
Gorga : Jurnal Seni Rupa

Volume 10 Nomor 01 Januari-Juni 2021

p-ISSN: 2301-5942 | e-ISSN: 2580-2380

dan kondisi lokal. Keseluruhan wujud tersebut menyiratkan performansi dalam bentuk kegiatan dan peristiwa. Tradisi lisan yang diperformansikan dapat terlihat karakter pemiliknya. Hal tersebut dikarenakan tradisi lisan merepresentasikan fenomena-fenomena kehidupan keseharian ke dalam bentuk pertunjukan. Demikian pula halnya tradisi badondong yang berkembang di desa Danto Kecamatan Kampar Timur, Kabupaten Bangkinang, propinsi Riau. Istilah badondong bersal dari bahasa bangkinang yang berarti berdendang dalam pengertian sebuah cara untuk mengungkapkan rasa atau hasrat dari dalam diri seseorang dengan menggunakan vokal berupa dendang khas dari masyarakat Danto itu sendiri. Biasanya sebelum melakukan badondong ini diawali dengan pantun yang bersajak A-B. Menurut Purnomo (2018) setidaknya terdapat empat belas warisan budaya tidak berupa benda di Riau dan Kepulauan Riau diantaranya di daerah Danto yaitu badondong, batobo, dikiu gubano.

Badondong atau pantun badondong lahir secara turuntemurun di daerah Kampar. Sastra lisan ini ada ketika tradisi bergotong-royong yang dikenal dengan sebutan batobo dilaksanakan. Masyarakat Kampar yang beraktifitas di ladang atau sawah memiliki ikatan rasa kebersamaan dalam bekerja atau bertani. Pada saat mereka berada di hutan, ladang atau sawah untuk mencari kayu, menyemai padi, menyadap karet dan sebagainya, mereka saling berpantun dengan cara mendendangkan yang oleh masyarakat setempat disebut badondong. Budaya badondong seiring waktu kemudian berkembang menurut pola pikir atas dasar kesepakatan yang terwariskan secara turn-temurun dari leluhur mereka. Maka nilai-nilai yang terkandung dalam badondong baik isi maupun maknanya terwujud sesuai tata nilai adat yang dipakai dalam mengatur kehidupan masyarakat.

Badondong dalam mengekspresikannya sering pula didendangkan dengan menyerakkan atau meninggikan suara secara bersahut-sahutan. Hal inilah yang menciptakan suasana riuh penuh kegembiraan yang kemudian berpengaruh pada semangat bekerja dan pelepas kepenatan. Jika dilakukan di dalam hutan maka badondong tersebut dapat menghilangkan rasa takut karena terasa ramai dan berkawankawan. Diantara nilai-nilai yang ada pada badondong ialah menyangkut pendidikan karakter, seperti pantun berikut: Matilah lintah dipaluik lumuik cu Di tongah-tongah cu kosiokbadoai oo hoi Apo perintah kan den tuwuik yo cu Asalkan jan kasiohkan bacoai oo hai Onde cu (Matilah lintah dipalut lumut ya bang Di tengah-tengah bang pasir berderai Apa perintah akan saya turuti ya bang 
Asalkan jangan kasihkan bercerai oo hai Aduh bang) Bentuk pantun pada badondong sama seperti pantun biasa yang terdiri dari empat baris, baris pertama dan kedua sebagai sampiran dan baris ketiga serta keempat sebagai isi. Polanya a,b;a,b.

Dilihat secara musikal, melodi vikal dari badondong baibo cukup sederhana, dan selalu diulang-ulang dan monoton, namun melodi vokal yang hadir, menjadi inspirasi pengkarya untuk pangamatan yang akan dijadikan sebuah komposisi musik. Pengamatan yang dilakukan penulis yaitu mengamati bentuk struktur melodi vokal badondong baibo ini sehingga menimbulkan ide-ide yang kreatif untuk membuat sebuah komposisi-komposisi baru dengan format orkestra yang diberi judul badondong baibo. Sumarjo (2000) menjelakan bahwa musik itu terjadi tidak lepas dari pengaruh jiwa atau perasaan imajinasi yang tinggi maka kreator seni membuat geragam ciptaan baru. Biasanya seniman akan menjadi besar karena bertolak dari bahan-bahan yang tercipta sebelumnya. Setiap seniman bukanlah manusia yang jatuh dari angkasa dan mampu menciptakan karya seni tampa dukungan karya seni yang telah tersedia di dalam masyarakat.

Rumusan penciptaan komposisi ini diwujudkan dalam sebuah pertunjukan yaitu musik instrumental dan vokal yang mengangkat kesenian badondong baibo menjadi sebuah pertunjukan musik instrumental yang kreatif dan inovatif dalam bentuk komposisi musik dengan format orketra. Dimana rumusan penciptaan menggunakan prinsip-prinsip ilmu musik konvensional. Sedangkan tujuan penciptaan ini adalah 1) untuk menghadirkan kesenian badondong baibo dengan konteks dan fungsi yang berbeda ke dalam komposisi musik modern dan mengembangkannya dengan menggunakan teknik konvensional, 2) untuk merealisasikan ide musikal yang di inspirasi dari kesenian badondong baibo dan menjadikannya sebuah komposisi musik yang baru.

\section{KAJIAN TEORI}

\section{Komposisi Musik}

Istilah komposisi sendiri berasal dari bahasa Jerman Kompenieren yang dicetuskan oleh seorang pujangga Jerman bernama Johann Wolfgang Goethe (1749-1832) yang memiliki arti cara menggubah musik dimana satu suara yang menjadi suara utama (lead) akan diikuti oleh suara-suara lain yang disusun, dikoordinasikan, ditata, dan dirangkai mengikuti suara utama. Menurut Kusumawati (2004: ii) komposisi merupakan proses kreatif musikal yang melibatkan beberapa persyaratan, yaitu bakat, pengalaman, dan nilai rasa. Sedangkan menurut Syafiq (2003:165)
Gorga : Jurnal Seni Rupa

Volume 10 Nomor 01 Januari-Juni 2021

p-ISSN: 2301-5942 | e-ISSN: 2580-2380

mengatakan komposisi adalah gubahan musik instrumental maupun vokal Dari pendapat tersebut dapat ditarik kesimpulan bahwa komposisi adalah suatu pengembangan ide musikal dan penggabungan dari elemen-elemen musik melalui pengetahuan, pengalaman, rasa, dan estetika untuk menjadikan sebuah sajian musik yang orisinal. Menurut Banoe (2003: 426) unsur bentuk komposisi musik adalah frase, periode, bentuk lagu satu bagian, dua bagian tunggal, tiga bagian tunggal, dua bagian majemuk, rondo, tema dan variasi, sonata. Unsur komposisi musik adalah syair, ritme dan pola ritme, metrum, melodi, harmoni, dinamik, warna bunyi, tekstur.Unsur struktur komposisi musik adalah motif, tema, variasi (semua unsur komposisi dapat divariasi), improvisasi. Menurut Wang, (2014) Karena musik adalah fenomena multimedia multidimensi, desain musik komposisi dapat dijelaskan pada beberapa tingkatan. "Elemen Musik" seperti, 1) Irama (ketukan, meteran, tempo, sinkopasi, politme, 2) Dinamika: (crescendo, decrescendo; forte, piano, dll.) 3) Melodi: (nada, jangkauan, tema) 4) Harmoni: (akor, progresi, kunci, nada suara,kesesuaian, disonansi) 5)Warna nada: (register, range) 6) Tekstur: (monophonic, polyphonic, homophonic), 7) Bentuk: (biner, terner, strophic, dll.).

\section{Instrumen Musik}

Instrumen berasal dari kata instrument (dalam seni musik) berarti alat musik atau bunyi - bunyian. Menurut Soewito (1996 : 13) instrumen musik adalah sarana untuk penampilan suatu kesenian. Dengan demikian, instrumen musik ialah alat yang digunakan untuk menghasilkan bunyi atau suara dalam menampilkan suatu produk kesenian. Hutagalung (2018) menjelaskan alat-alat musik (instrument musik) berperan sebagai media yaitu alat pengantar atau penyalur ide-ide komponis dalam suatu komposisi yang ditulis dalam bentuk partitur (tulisan musik). Dalam hal ini pemain musik melalui alat musiknya mewujudkan partitur dalam bentuk nada-nada yang aktual. Dengan kata lain si pemain menerjermahkan simbolsimbol nada atau not yang tertulis, ke ujud nada fisikal melalui medium berupa satu atau beberapa instrumen. Pada musik vokal, si penyanyi sekaligus berperan sebagai pemain dan medium.

Instrumen musik telah ada sejak manusia mengenal peradaban, dimana setiap suku bangsa (etnik) di seluruh penjuru dunia masing-masing memiliki musik etnik yang peran dan fungsinya berkaitan dengan siklus kehidupan masyarakatnya. Musik berperan sebagai medium dalam berbagai upacara ritual baik yang bersifat magis, adat-istiadat maupun hiburan. Menurut Mudjilah, (76: 2004) Secara umum instrumen musik 
apabila ditinjau dari sumber bunyinya terdiri dari 5 jenis yaitu instrumen musik pukul, instrumen musik tiup, instrumen musik petik, instrumen musik gesek dan instrumen vokal. Alat-alat musik sepanjang perjalanan sejarah kebudayaan senantiasa berkembang kendati dengan dinamika yang sangat lambat (evolusi) dari bentuk yang paling sederhana hingga pada bentuk baku seperti sekarang ini, yang sangat beragam baik bentuk, bahan, cara memainkan, karakter suara, dan berbagai spesifikasi lainnya.

\section{Badondong}

Budaya pantun Badondong lahir secara turun temurun Kabupaten Kampar Isi dan makna nilai-nilai pantun dalam Badondong berkembang berdasarkan pola pikir yang disepakati oleh kebiasaan leluhur mereka. Proses yang membudaya dalam pantun Badondong (pantun yang didendangkan), ada karena telah melalui proses kehidupan yang panjang di masyarakat. Jadi, dalam hal ini, isi dan makna nilai-nilai pantun Badondong lahir berdasarkan pola pikir yang disepakati oleh tata nilai adat yangdigunakan untuk mengatur kehidupan masyarakat setempat.

Menurut Neldawati (2015) Perbedaan pantun dengan pantun Badondong adalah adanya bunyi sisipan seperti onde diok..(aduh dik..), onde cu... (aduh cu..), o...oi cu (o...oo bang), cu (bang), dan diok (adik), diantara pantun yang dituturkan oleh si penutur itu sendiri. Bunyi sisipan yang terdapat pada pantun badondong berdasarkan pendapat Agustina melalui Sutami, Hermina (2005: 56) menjelaskan bahwa kata ondeh sayang, ondeh kanduang, ndeh da/diok, oi sansei, oi mamak, dan lain-lain, ditemukan dalam lagu yang berdistribusi di tengah kalimat (sesuai dengan fungsinya sebagai perantara tema dan rima). Secara umum, pantun badondong ini memiliki religius, kejujuran, bertanggung jawab, disiplin, kesetiaan, kasih sayang, kerjasama, peduli lingkungan dan sportivitas/ kasih sayang.

Amanriza (1989) menjelaskan ada 2 jenis badondong yang sampai saat ini masih dilestarikan oleh masyarakat Danto kecamatan Kampar Timur yaitu badondong sonang dan badondong baibo. Badondong sonang adalah salah satu jenis dondong gembira. Kebiasaan ini tidak asing lagi bagi masyarakat Kampar yang akan melakukan batobo di sawah atau gotong royong pada saat musim panen mereka. Batobo berasal dari bahasa Bangkinang Riau yang artinya gotong royong. Pada masyarakat Danto kegiatan batobo ini dijadikan sebagai ritual yang wajib dilakukan secara bergantian. Badondong yang dilakukan pada ritual batobo tersebut dilakukan dengan tujuan untuk 1) mengurangi rasa lelah, 2) agar bersemangat, 3) membina rasa kebersamaan dari masing-masing individu. Sedang badondong baibo biasanya dilakukan pada saat hasil panen gagal atau ketika seseorang mengalami patah hati dalam percintaan, serta hajatan tidak terkabulkan. Badondong baibo ini selalu dilakukan masyarakat Danto secara sepontan baik tempat ataupun waktunya. Tujuan badondong baibo adalah untuk memberitakan bahwa perasaan sedih dan untuk mengurangi rasa sedih.

Di daerah Danto sebelum badondong baibo tersebut diawali dengan pantun yang berbentuk A-B seperti contoh berikut;

Ocu..kain buok kain palampin di jomu ughang suboang. Deen buok lai musikin kan apo pulo dek ughang.

Artinya; Abang kain jelek kain usang dijemur orang daratan seberang. Saya jelek sekaligus miskin apa gunanya bagi orang.

\section{METODE PENELITIAN}

\section{Tahap Pengumpulan Data}

Dalam proses penggarapan komposisi musik ini, komposer berangkat dari referensi tulisan, dokumentasi audio-visual, wawancara dengan beberapa orang seniman dan praktisi seni kabupaten Kampar. Kemudian penggarap jadikan sebagai bahan acuan untuk penggarapan komposisi musik ini.

\section{Tahap Proses Penciptaan}

Pada tahap ini pengkarya menotasikan melodi badondong baibo kemudian mengembangkannya dengan teknik-teknik ilmu musik konvensional yang telah mempunyai sistem dan peraturan yang baku, diantaranya menentukan; a). Menentukan tema yang kemudian dijadikan sebagai tema pokok dalam pengarapan ini, b). Menentukan bentuk garapan dan teknik-teknik pengembangan motif yang digunakan, c). Membuat condenscore untuk memilih harmoni, filler, dan counter melodi yang kemudian di orkestrasikan dengan media komputer. Progaram yang digunakan adalah sibelius, d). Menentukan instrument yang akan digunakan dalam komposisi ini dan menentukan pemain yang akan dimainkan instrument yang telah dipilih. Adapun instrument yang dipakai dalam komposisi ini adalah; vokal, flute, oboe, clarinet, basson, horn, trompet, trombone, tympani, cymbale, violin 1, violin 2 viola, cello, contrabass.

\section{Tahap Evaluasi}

Tahap ini akan menjelaskan karya dalam bentuk tulisan dan pertunjukan instrument. Kemudian tahap evaluasi 
dilanjutkan dengan perbaikan tulisan dan komprehensif yang dilakukan setelah pertunjukan berlansung.

\section{HASIL DAN PEMBAHASAN}

\section{Hasil}

Penciptaan komposisi ini menghasilkan sebuah pertunjukan musik instrumental yang kreatif dan inovatif dalam bentuk komposisi musik dengan format orketra yang diawali dengan adlibitum vocal dari badondong baibo, dengan tujuan untuk memperkenalkan tema asli yang akan digarap dimana vocal tersebut akan dibawakan beriringan dengan instrumen flute. Bagian ini terdiri dari 116 birama dengan tempo andante (kecepatan 75-80 langkah permenit) dan tempo alegro, dengan sukat $4 / 4$. Berikut dokumentasi vocalis badondong baibo.

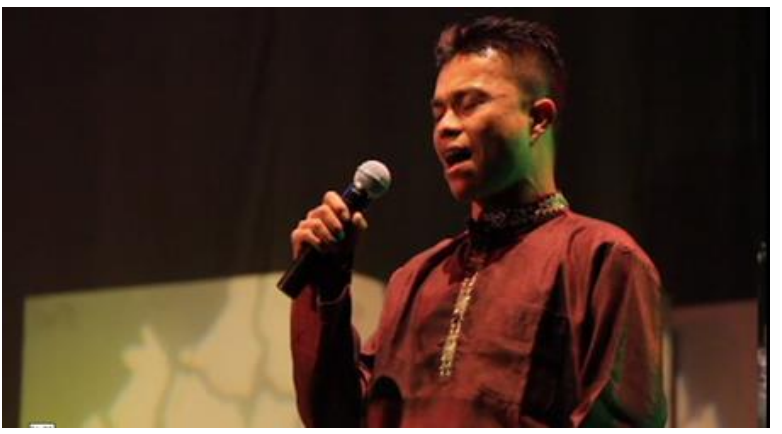

Gambar 1. Vocalis Badondong Baibo (Herdianto, 2021)

Skema bagaian satu dalam komposisi ini terdiri dari;

\section{1). Intro}

Intro dimulai dari birama 1 sampai dengan 24. Dalam bagian intro ini vocal dari badondong baibo akan dibawaka beriringan dengan instrumen flute. Pada bagian intro ini lagu badondong baibo yang sudah ditranspuse ke tangga nada $\mathrm{E}$ minor dibawakan secara free rhytem dimana flute dan pendondong akan bersahut-sahutan.

\section{2). $\mathbf{A}(\mathbf{a}+\mathbf{a})$}

Pada birama 7-14 adalah tema utama dari karya ini dimana tema asli dari melodi vocal badondong baibo dikembangkan dengan teknik augmentasi, pada birama ini melodi hanya dibawakan oleh instrumen cotra bass.

\section{3). $\mathbf{A}^{\prime}\left(\mathbf{a}^{\prime}+\mathbf{b}^{\prime}\right.$ '+b')}

Kalimat A' terdiri dari tiga frase seperti yang terlihat dari birama 15-29, (a') dan (a'") adalah kalimat antesiden, (b') sebagai kalimat konsekwen kalimat. Kalimat (a) dimulai dari birama 15-19 melodi dibawakan oleh instrumen cello dan contrabass sebagai root, dilanjutkan dengan kalimat (a') dari b irama 2024 dimana viola hadir sebagai harmoni, birama 25-28
Gorga : Jurnal Seni Rupa

Volume 10 Nomor 01 Januari-Juni 2021

p-ISSN: 2301-5942 | e-ISSN: 2580-2380

adalah kalimat konsekwen, pada kalimat konsekwen ini terdapat pengembangan tema yang menggunakan teknik retrogade. Secara keseluruhan pada kalimat A' terdapat teknik orkestrasi yang dimulai dari instrumen yang minimalis semakin banyak.

\section{4). A"'(a"'+b"')}

Kalimat (a" ') adalah antesiden, kalimat ini mulai dari birama 29-33 sedangkan kalimat (b') adalah kalimat konsekwen dimulai dari birama 34-37. Untuk orkestrasi flute berperan sebagai pembawa melodi, oboe, clarinet, violin II, viola, sebagai harmoni melodi, basson, cello, contrabass sebagai melodi ritme, horn dan violin I sebagai couter melodi. Sedangkan pada birama 36-37 terdapat teknik canon dibawakan oleh string section.

\section{5). $\mathbf{A} ",(a, "=b "$,}

Pada bagian kalimat (a"') adalah antesiden dimulai dari birama 38-42, pada birama tersebut instrumen yang digunakan adalah horn sebagai melodi dan basson sebagai root, dilanjutkan pada kalimat (b',') sebagai kalimat konsekwen pada birama 43-46, pada kalimat ini instrumen flute, oboe, clarinet, horn, terompet, trombon, violin I, violin II, viola, cello membawakan melodi secara yudisono. Contra bass sebagai root, basson sebagai counter melodi dan timpani berfungsi sebagai filler dengan tujuan untuk memberi suasana yang tidak monoton.

\section{6). B (a+a+b+b')}

Pada bagian ini terdapat kalimat (a) dan (a') sebagai kalimat antesiden, kalimat tersebut dimulai dari birama 47-53, sedangkan kalimat (b) dan (b') dimulai pada birama 54-60. Untuk orkestrasi pada bagian ini oboe, clarinet, horn, terompet, violin I, violin II, cello dimainkan secara yudisono, basson dan contra bass sebagai root, timpani sebagai sebagai filler. Pada birama 55 horn yang tadinya sebagai melodi difungsikan sebagai filler agar melodi tidak monoton. Selanjutnya pada birama 57 terdapat poco accel dimana melodi berangsur-angsur cepat dengan tujuan menhantarkan tempo adante ke tempo moderato.

\section{7). Interlude (a+b+a'+b'+b')}

Pada birama 60-65 melodi vokal dari badondong baibo dihadirkan kembali beriringan dengan instrummen flute dan timpani sebagai filler, selanjutnya pada birama 69 cello akan dimainkan melodi dan conta bass sebagai root, pada birama 71 melodi cello akan di doble oleh instrumen oboe dan flute pada birama 7273. Pada birama 74-88 oboe, clarinet, bsson, horn, secara bergantian membawakan filler terompet, trompon dan contrabass sebagai harmoni. Cello sebagai rhytim 


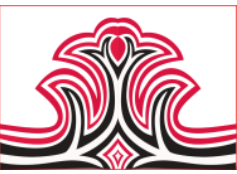

harmoni, violin I, violin II, viola secara bersahutsahutan akan membawakan counte melodi, seterusnya pada birama 89 melodi dibawakan secara yudisono. Adupun fugsi dari timpani ada dibagian ini interlude ini adalah sebagai pengisi suasana dan pengantar emsi pada birama 89 hingga birama berikutnya.

\section{8). A""(a+a)}

Kalimat ini adalah pengulangan dari kalimat pertama akan tetapi di orkestrakan dengan teknik dan tempo yang beda kalimat (a',',) ada pada birama 90-94 seterusnya kalimat (a",') pada barima 9599. Untuk orkestrasi melodi dibawakan oleh flute dan violin I, counter melodi basson, dan cello harmoni melodi dibawakan oleh oboe, clarinet, horn, terompet, violin II, rhytim harmoni trompon dan contra bass, sedangkan timpani dan cymbal dihadirkan untuk menaikan emosi.

\section{9). A',(a"'+a')}

Kalimat ini adalah pengulangan dari kalimat sebelumnya dimana yang berubah hanyalah intrumen pembawa filler, dan rhytem dari timani dan chymbal yang lebih banyak dengan tujuan emosi lagu lebih dinaikan.

\section{0). Codeta}

Kalimat codeta ini terdiri dari 7 birama dimana pada kalimat codeta tempo diturunkan kembali dari tempo moderato ke tempo adente.

\section{Pembahasan}

\section{1). Konsep Penciptaan}

Banyak inspirasi atau ide-ide dan gagasan untuk membuat sebuah karya seni, baik itu kesenian tradisi maupun kesenian modern yang berangkat dari kebudayaan masyarakat atau keadaan fenomenafenomena yang terjadi dalam kehidupan kita, itu semua tidak terlepas dari keberadaan sosial masyarakat di setiap daerah dan lingkungan tempat kita berada. Menciptakan sebuah karya seni dapat melalui pengalaman berkesenian yang diperoleh dari setiap individu masyarakat dalam kesehariannya, sebagaimana yang telah diungkap Sumarjo, (2000).

yaitu pengalaman yang dialami oleh penikmat seni atau penanggap seni seperti dalam pengalaman sehari-hari, maka pengalaman seni juga merupakan sesuatu pengalaman utuh yang melibatkan perasaan, pikiran, penginderaan dan sebagai intuisi manusia. Hanya saja pengalaman seni berlansung dalam kualitas pengalaman tertentu yang kadang-kadang tidak sama dengan pengalama sehari-hari.
Gorga : Jurnal Seni Rupa

Volume 10 Nomor 01 Januari-Juni 2021

p-ISSN: 2301-5942 | e-ISSN: 2580-2380

Seperti halnya kebiasaan yang dilakukan masyarakat Danto yang dikenal dengan badondong baibo. Dengan khasnya yang unik badondong baibo tersebut menjadi inspirasi pengkarya dalam penggarapan komposisi ini. Adapun notasi dari badondong baibo yaitu;

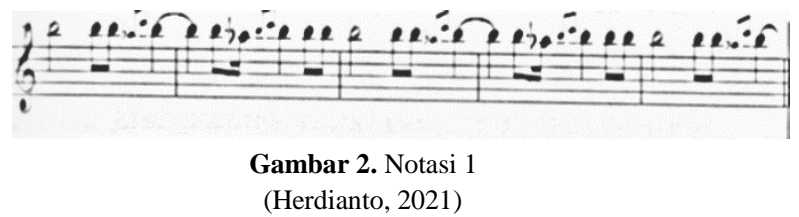

\section{(1). Notasi 1 Transkip Melodi "Badondong Baibo"}

Melodi ini akan ditranspuse ketangga nada $\mathrm{E}$ minor dan dikembangkan sesuai dengan disiplin ilmu musik konvensional seperti retroget, sekwen, imitasi, diminusi, augmentasi, canon, membuat perangkat bass dengan teknik dessending (menurun) serta menggunakan filler-filler untuk menghindari bentuk monoton

\section{2). Kajian Sumber Penciptaan}

Dalam proses pengarapan pengkarya memperoleh sumber dari informan permerhati seni kabupaten Kampar melalui wawancara. Kemudian pengkarya juga mendapatkan audio-visual yang direkam lansung dari informan tersebut. Tidak hanya dari informan pengkarya juga melakukan studi literatur dan melakukan studi kepustakaan. Studi literatur menjadi pijakan awal sebelum melakukan penciptaan. Studi literatur bisa digunakan untuk pencarian ide-ide penciptaan, kebaruan penciptaan, mempertajam ide, mencari metode yang cocok, atau bahkan untuk melakukan ATM (Amati, Tiru, Modifikasi). Jujur saja, tidak ada penciptaan yang benar-benar baru $100 \%$, selalu ada irisan dan duplikasi. Yang penting adalah dalam melakukan penciptaan tidak boleh menjiplak, plagiat atau mengulang mentah-mentah penciptaan yang sudah ada.

\section{3). Pendekatan Konseptual Penciptaan}

Musik akan selalu berkembang seiring terjadinya perubahan dalam bentuk dari zaman ke zaman yang lainnya, begitupun dengan fungsi dari musik itu sendiri, seperti halnya badondong baibo yang dahulunya hanya bisa didengar pada saat-saat tertentu akan tetapi pada saat ini sudah dapat dihadirkan dalam bentuk pertujukan yang dikolaborasikan dengan musik-musik tradisi dan modern. Kesenian badondong baibo ini telah menjadi sumber inspirasi bagi komposer untuk menggarap sebuah komposisi musik berdasarkan ilmu musik konvensional dengan menggunakan teknik pengembangan motif seperti; retroget, repetisis, augmentsi, diminusi, dengan memadukan bentuk 


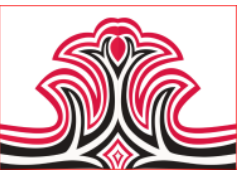

penggarapan canon dan pengembangan harmoni, setelah melakukan pengamatan, komposer melakukan surve keaktifan instrument yang ada di jurusan musik. Selanjutnya membuat format garapan dan memilih pemain yang lebih mampu dibidangnya masing-masing untuk mewujudkan garapan komposisi musik ini. Adapun penjabaranya adalah sebagai berikut;

\section{(1). Bentuk Garapan}

Bentuk garapan dalam komposisi ini adalah bentuk bebas, maksudnya tidak terikat dengan bentuk komposisi yang sudah ada seperti sonata dan rondo. Namun masih mempunyai kerangka struktur yang jelas, pasti, dan harmoni konvensional dengan format pertujukan musik orkestra. Dibagian introduksi (pembuka) melodi badondong baibo digarap dan dikembangkan dengan teknik imitasi dalam tangga nada E minor harmonic tone dengan sukat 4/4 dalam tempo andante. Dimana melodi dari badondong maibo tersebut dibawakan oleh vokal dan flute dengan tujuan untuk memperkenalkan tema asli dari badondong baibo tersebut.

Selanjutnya tema dari badondong baibo dikembangkan lagi dengan teknik augmentasi dan dijadikan tema pokok dalam pengembangan bagian I, didalam tangga nada E minor harmonic tone sukat 4/4 dengan tempo andate dan moderato. Dibagian I ini, untuk kalimat consequen tema pada kalimat antesedent dikembangkan lagi dengan teknik retrogade, seterusnya memberi transisi secara yudisino sebagai pengantar kalimat yang lainnya dan menambahkan filler agar tema tidak monoton.

\section{(2). Pemilihan Instrumen}

Instrumen yang digunakan dalam komposisi ini antara lain flute, oboe, clarinet, basson, trompet, horn, trombon, biola 1, biola alto, cello, contrabass, timpani, symbal, dan vokal.

\section{(3). Pemilihan Pemain}

Instrumen yang digunakan dalam komposisi ini antara lain flute, oboe, clarinet, basson, trompet, horn, trombon, biola 1, biola alto, cello, contrabass, timpani, symbal, dan vokal.
Gorga : Jurnal Seni Rupa

Volume 10 Nomor 01 Januari-Juni 2021

p-ISSN: 2301-5942 | e-ISSN: 2580-2380

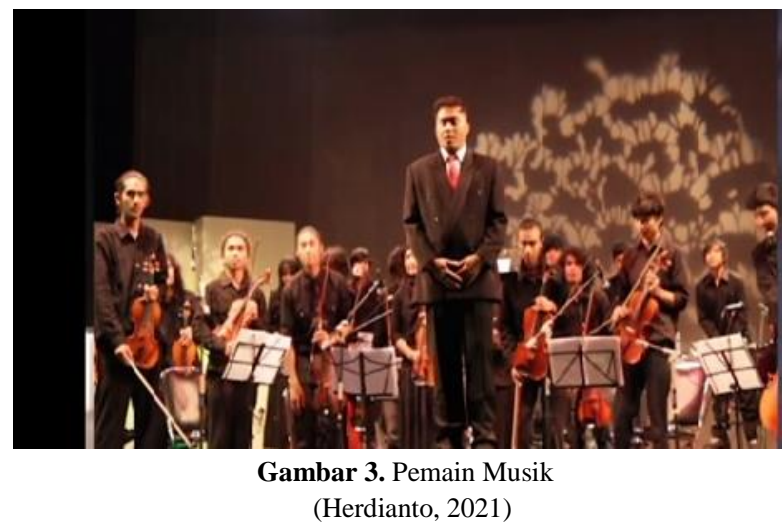

4). Analisis Karya Komposisi Musik Badondong Baibo dalam Bentuk Komposisi

\section{(1). Struktur Bentuk}

Komposisi musik ini digarap dalam bentuk bebas yang menggunakan format orkestra. Bagian ini menghadirkan vokal melodi badondong baibo yang sudah ditranspuse ke tangga nada dasar E minor kemudian melodi vocal tersebut dikembangkan dengan teknik augmentasi, diminusi, retrogade, imitasi, sekuence. Bagian ini terdiri dari 116 birama, birama 159 dimainkan dalam tempo andante dilanjutkan pada birama 60-116 dalam tempo moderato dengan sukat 4/4 yang prinsip harmoninya masih menggunakan sistem chord by thirds.

\section{(2). Harmoni}

Harmoni adalah elemen musik yang mempelajari keselarasan bunyi. Keselarasan bunyi itu dapat dilihat dari melodi yang disusun secara vertikal yang disebut cord. Sedangkan menurut Lailia , D.R, (2016) harmoni adalah keselarasan; keindahan. Dengan kenyataan itu maka pengetahuan harmoni akan terbentuk pada dua kemungkinan: selaras atau tidak selaras; indah atau tidak indah. Hal ini dipertegas Banoe (2003: 192) kesemuanya dibahas dalam ilmu pengetahuan harmoni musik. Seiring perkembangan ilmu musik sekarang harmoni didukung oleh pengetahuan asasi bahwa acord merupakan fungsi yang bersifat terkait dengan struktur. Harmoni dalam komposisi ini hanya menggunakan harmoni dengan sistem chord by thirds (penyusunan cord berdasarkan jarak vertical terts). Untuk lebih jelasnya dapat dilihat pada gambar berikut:

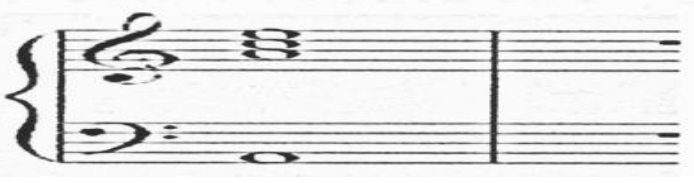

Gambar 4. Chord by Third (Herdianto, 2021) 


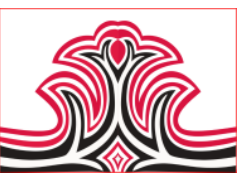

(3). Melodi

Melodi adalah jangkauan pola yang pasti akan tinggi rendahnya nada, yang sah menjadi musik bila ditunjang dengan gagasan yang memadukannya dalam suatu kerja sama dengan irama, tempo, bentuk. Turek (1988: 80-81) menjelaskan melodi dalam pengertian umum dapat diartikan sebagai rangkaian atau urutan dari nadanada didalam irama. Nada-nada tersebut biasanya tersusun dalam satu kesatuan yang lebih besar. Jamalus (1998: 16) menjelaskan melodi adalah susunan rangkaian nada ( bunyi dengan rangkaian teratur) yang terdengar berurutan serta berirama dan mengungkapkan suatu gagasan pikiran dan perasaan. Sedangkan menurut Ali (2006: 56) melodi adalah rangkaian nada-nada dalam notasi yang dibunyikan secara berurutan. Dari ketiga penjelasan tersebut di atas dapat disimpulkan bahwa.. Melodi adalah serangkaian nada-nada dalam waktu tertentu yang dapat dibunyikan sendirian, yaitu tanpa iringan, atau dapat merupakan bagian dari rangkaian akord dalam waktu tertentu. Rangkaian nada-nada tersebut akan membentuk pola irama yang turun naik dan terdengar berurutan serta berirama dan menungkapkan suatu gagasan. Yang menjadi pokok dalam komposisi ini dapat dilihat pada notasi dibawah ini:

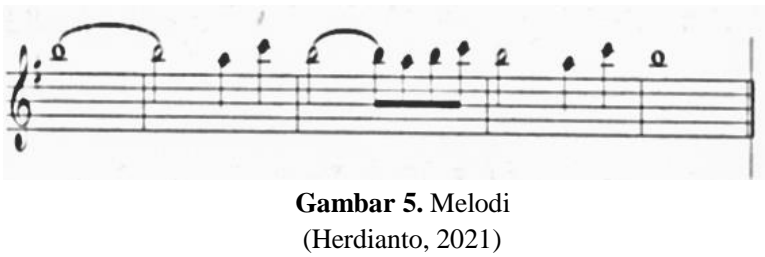

\section{(4). Tekstur}

Setiap aliran musik memiliki ciri-ciri tersendiri yang membuat sebuah aliran tertentu dapat dikenali, salah satunya adalah tekstur. Dalam komposisi ini tema yang ada selalu diulang-ulang dengan instrument yang berbeda. Melodi secara bergantian antara instrumen yang satu dan lain sudah menjadi ciri-ciri utama, baik dari garis melodi di wilayah hight, midle, hingga low dan sebaliknya, penempatan itu disesuaikan dengan range (wilayah jangkauan nada dari bawah hingga atas) masing-masing instrument. Sedangkan untuk penggunaan acord atau pengolahan harmoni dalam komposisi ini hanya menggunakan sytem chord by third.

\section{(5). Canon}

Canon adalah komposisi kontrapung yang diaminkan secara bersahut-sahutan. Canon at the unison adalah apabila kalimat susulanya merupakan imitasi atas kalimat pertama. Aziza, M. R (2013) mejelaskan Canon adalah sebuah teori musik yang mempunyai arti
Gorga : Jurnal Seni Rupa

Volume 10 Nomor 01 Januari-Juni 2021

p-ISSN: 2301-5942 | e-ISSN: 2580-2380

sebuah komposisi kontrapungtal yang mempekerjakan melodi dengan satu atau lebih imitasi dari melodi, yang dimainkan setelah durasi tertentu (misalnya, seperempat istirahat, dll). adapun karakter canon antara lain: (1) berupa pengulangan/ imitasi melodi (2) terdiri dari melodi leader dan follower dengan durasi tertentu (3) melodi follower dapat mengimitasi melodi leader berupa ritme yang sama, interval yang sama, transformasi dari ritme/ intervalnya (4) adanya kesan melodi yang bertumpuk dan bersahut-sahutan. setelah mengenali karakternya, perlu juga mempelajari sheet/ partitur lagu yang mengandung teori canon.

\section{KESIMPULAN DAN SARAN}

\section{Kesimpulan}

Karya seni apapun wujudnya, dapat diangkat dari peristiwa apa saja, baik itu kebiasan sehari-hari dalam kehidupan masyarakat, maupun fenomena-fenomena yang terjadi di dunia ini. Sama halnya dengan menidurkan anak di daerah kecamatan Tanah Sepanggal Lintas. Kegiatan menidurkan anak didalam buiai telah dilakukan sejak dahulu. Para ibu-ibu melantunkan lagu-lagu agar anaknya tidur dengan tenang. Lagu-lagu yang dilantunkan tidak ditetaapkan oleh sebuah lembaga atau sebuah kesepakatan musyawarah. Lagu tersebut lahir dari si-ibu sendiri sehingga menjadi kebiasaan sehari. Lagu "nandungnandung" merupakan lagu buai anak di kecamatan Tanah Sepanggal Lintas. Uniknya kaum ibu selalu membawa anaknya yang masih kecil untuk ikut bekerja disawah, namun si-anak bukan bekerja seperti apa yang dilakukan ibunya, si-anak akan bermain dengan sendirinya sehingga waktu istirahat siang maka si-anak akan mengantuk kerena telah kelelahan bermain. Disaat inilah si-ibu akan menidurkan anaknya dengan lantunan lagu "nandung-nandung" sampai anaknya tertidur, sehingga si-ibupun kembali bekerja dengan tenang tampa menghawatirkan anaknya yang tertidur. Secara garis besar dari keseluruhan studi ini dapat disimpulkan bahwa; a) menggarap sebuah komposisi yang berangkat dari sebuah kesenian bukanlah perkara yang mudah, selain harus memahami, kita juga dituntut untuk mempelajari latar belakang dari kesenian tersebut, b) badondong adalah komposisi musik baru yang bersumber dari melodi vocal badondong baibo yang terdapat didaerah Danto kecamatan Kampar Timur, c) material komposisi ini adalah potonganpotongan melodi "nandung-nandung" yang dikembangkan dengan tidak menghilangkan nuasa melodi pokok "nandung-nandung", d) vokal dari badondong baibo dibawakan oleh seorang vokalis untuk memperkenalkan tema pokok dalam penggarapan komposisi ini, e) komposisi digarap dengan format orkestra dalam sebuah pertunjukan seni, 


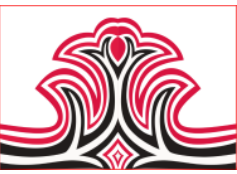

f) badondong ini adalah sebuah komposisi musik yang diciptkan dengan menggunakan banyak pengembangan, dimana komposisi musik ini dihadirkan dalam konteks prtunjukan seni. Digarap tidak dengan menggunakan instrumen orkestra yang dipadukan dngan nyanyian "badondong baibo" itu sendiri. Berikut dokumentasi pertunjukan komposisi badondong baibo.

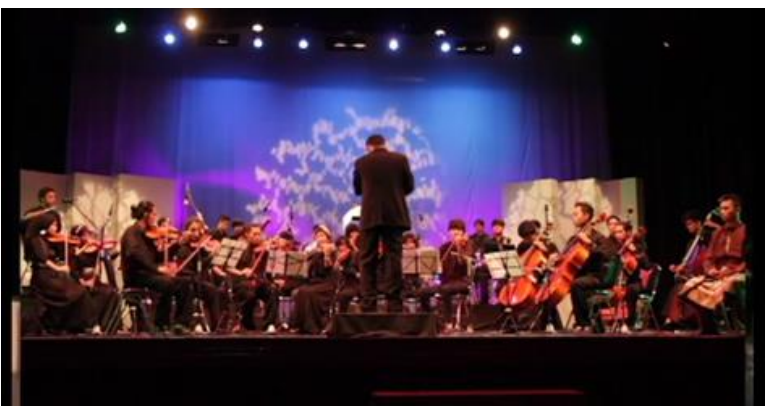

Gambar 6. Pertunjukan (Herdianto, 2021)

\section{Saran}

Selama proses penciptaan dan proses penulisan karya musik "Komposisi Musik Badondong Baibo Dalam Musik Instrmental" ada beberapa saran yang dapat dijadikan masukan kepada pengkarya seperti; 1). Bagi pencipta komposisi musik selanjutnya, dapat dijadikan acuan menambah suatu perbandingan untuk didengar, serta memberikan pengetahuan tentang komposisi musik, dengan harapan dapat menciptakan karya komposisi musik dengan kreativitas, memunculkan inovasi-inovasi baru, 2). Dalam penciptaan sebuah karya musik sebaiknya terlebih dahulu menentukan bentuk musik apa yang ingin diciptakan agar memudahkan proses pembahasan dan analisis, 3). Kepada Dewan kesenian daerah dan semua pihak yang berkecimpung dalam dunia seni tradisi di Nusantara, khususnya masyarakat Kampar-Riau agar tetap melestarikan kesenian badondong, 4). Dalam rangka melestarikan kesenian Tradisional badondong hendaknya tetap dibarengi dengan peningkatan kualitas pemain dan peralatan yang ada serta semua yang terlibat di dalamnya sehingga kesenian tradisional badondong tetap melekat di hati masyarakat mengingat kesenian modern sekarang ini terus berusaha merebut hati masyarakat dengan menampilkan kolaborasi musik berkelas.

\section{DAFTAR RUJUKAN}

Aziza, M. R., Soemardiono, B. (2013). Canon, Sebuah Teori Musik sebagai Tema Objek Rancang Sekolah Tinggi Seni Pertunjukan Indonesia. Jurnal Sains dan Seni Pomits. 2(2),
Gorga : Jurnal Seni Rupa

Volume 10 Nomor 01 Januari-Juni 2021

p-ISSN: 2301-5942 | e-ISSN: 2580-2380

Amanriza, dkk. (1989). Koba Sastra Lisan Orang Riau.

Pekanbaru: Dinas Kebudayaan dan Pariwisata Provinsi Riau.

Baran, Stanley J. (2011). Pengantar Komunikasi Massa: Literasi Media dan Budaya, Edisi Kelima Buku Satu. Jakarta: Salemba Humanika.

Banoe, Pono. (2003). Kamus Musik. Yogyakarta: Kanisius.

Esten, M. (1990) Sastra Indonesia dan Tradisi Subkultur. Bandung: Angkasa.

Lailia, D. R. (2016). Tinjauan Harmoni Pada Karya Musik "True Love Of Family”. Jurusan Pendidikan Sendratasik: Fakultas Bahasa dan Seni Universitas Negeri Surabaya.

Jamalus. (1988). Pengajaran Musik Melalui Pengalaman Musik. Jakarta: Proyek Pengembangan Tenaga Kependidikan Direktorat Jendral Pendidikan Tinggi.

Kusumawati, Heni. (2004). Komposisi Dasar. Yogyakarta: Fakultas Bahasa dan Seni. Universitas Negeri Yogyakarta.

Herdianto, F. (2021). "Badondong Baibo". Hasil Dokumentasi Pribadi. 2021, ISI Padangpanjang.

Hutagalung, R. J. (2018). Klasifikasi Instrumen Musik pada Ensembel Musik Tradisional Batak Toba. Jurnal Christian Humaniora, 2(2), 114126.

Mahdayeni, M., Alhaddad, M. R., \& Saleh, A. S. (2019). Manusia dan Kebudayaan (Manusia dan Sejarah Kebudayaan, Manusia dalam Keanekaragaman Budaya dan Peradaban, Manusia dan Sumber Penghidupan). Tadbir: Jurnal Manajemen Pendidikan Islam, 7(2), 154-165.

Maran, Rafael Raga. (2007). Manusia dan Kebudayaan dalam Perspektif Ilmu Budaya Dasar. Jakarta: Rineka Cipta.

Mudjilah, H. S. (2004). Teori Musik (Diktat Kuliah). Yogyakarta: Jurusan Sendratasik Program Studi Pendidikan Seni Musik, FBS-UNY Yogyakarta.

Juita, N. (2015). Nilai-nilai Pendidikan Karakter dalam Pantun Badondong Masyarakat Desa Tanjung Bungo Kecamatan Kampar Timur Kabupaten Kampar. Bahasa, Sastra, dan Pembelajaran, 3(1)

Purnomo. (2018) Warisan Budaya Takbenda (WBTb) Hasil Penetapan Kemendikbud 2013 s.d. 2018 Untuk Wilayah Kerja BPNB Kepulauan Riau Provinsi Kepulauan Riau dan Riau. Riau: Balai Pelestarian Nilai Budaya Kepulauan Riau. 
Sahar, S. (2016). Merintis Jalan: Membangun Wacana Pendekatan Antropologi Islam. Jurnal Al Adyaan; Jurnal Sosial dan Agama, 1(02).

Syafiq, Muhammad. (2003). Ensiklopedia Musik Klasik. Yogyakarta: Adicita Karya Nusa.

Sibarani, R. (2015). Pendekatan antropolinguistik terhadap kajian tradisi lisan. Retorika: Jurnal Ilmu Bahasa, 1(1), 1-17.

Sutami, Hermina. (2005). Ungkapan Fatis dalam Pelbagai Bahasa. Depok: Rumah Printing.

Sumardjo, Jakob. (2000). Filsafat Seni, Penerbit ITB: Bandung.

Wang, A. (2014, May). The Expression of Emotion and Feeling in Music Composition. In International Conference on Education, Language, Art and Intercultural Communication (ICELAIC-14) (pp. 636-638). Atlantis Press.

Turek, Ralp. (1988). Concepts and Application. New York: The University of Akron.

Yohana, N., \& Husmiwati, K. (2015). Kaidah interaksi komunikasi tradisi lisan basiacuang dalam adat perkawinan Melayu Kampar Riau. Jurnal Penelitian Komunikasi, 18(1), 43-56. 